This Section of Epidemiology and Psychiatric Sciences appears in each issue of the Journal and is dedicated to all forms of creative production born of an intimate and individual urge, often secretive, unbound from the conventional art system rules. Through short descriptions of the Outsider art work of prominent artists and new protagonists often hosted in community mental health services, this section intends to investigate the latest developments of the contemporary art scene, where the distances between the edge and the center are becoming more and more vague.

Carole Tansella, Section Editor

\title{
Spiritualism, trauma and the art of Madge Gill
}

\author{
D. Wojcik* \\ English and Folklore Studies, University of Oregon, Eugene, Oregon, USA
}

Received 15 March 2017; Accepted 20 March 2017; First published online 10 May 2017

Key words: Art brut, outsider art, spiritualism, trauma.

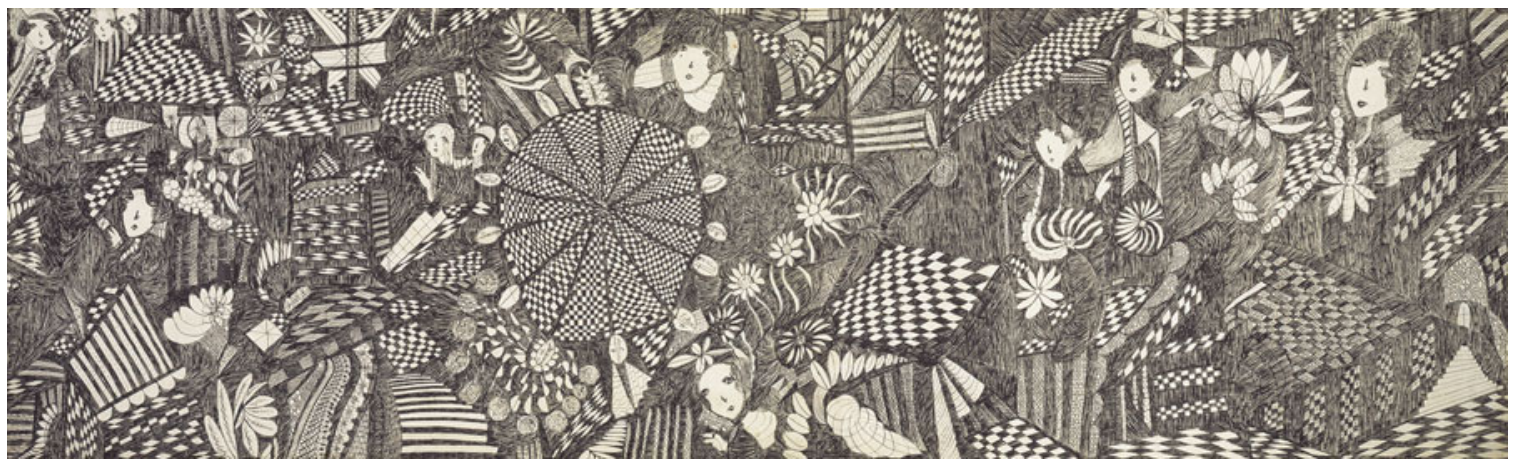

Fig. 1. Madge Gill, Untitled, not dated, ink on paper (no dimensions provided). Courtesy of abcd collection/Bruno Decharme, Paris.

The Spiritualist Madge Gill (born Maude Ethel Eades; 1882-1961) often is considered the embodiment of outsider artistry, as one of the most prolific artists championed by Jean Dubuffet and other advocates of art brut. Gill created her substantial oeuvre in a seemingly hypnotic state during times of grief and trauma throughout her life. Her art is characterised by its dizzying complexity, a vortex of swirling geometric patterns and labyrinthine designs, with shifting stairways,

\footnotetext{
* Address for correspondence: Dr D. Wojcik, English and Folklore Studies, 1286 University of Oregon, Eugene, Oregon, 97403-1286, USA.

(Email: dwojcik@uoregon.edu)
}

off-kilter architectural forms, interlocked zigzags and checkered areas, spirals and mazes, and disembodied female faces suspended and peering at the viewer through the free-flowing ectoplasmic forms of the compositions - portals to other worlds (Fig. 1). These mesmerising artworks reveal Gill's own unique creative abilities, yet they also exist comfortably within the larger context of the Spiritualist movement that emerged in the nineteenth century, expressing Gill's identity as a medium and the realms she envisioned and depicted through her entranced artistic designs.

Gill was born out of wedlock in the East End of London and she was raised largely in seclusion by her unmarried mother Emma to avoid public shame 


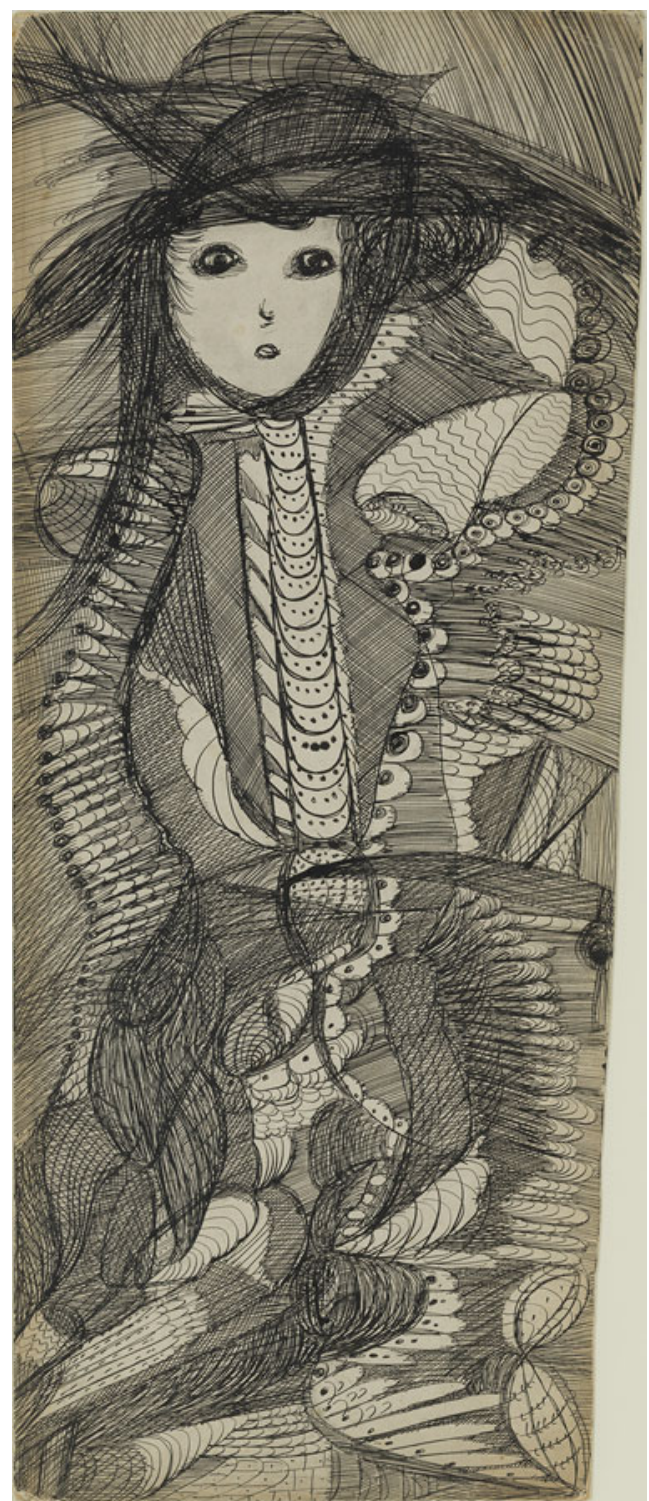

Fig. 2. Madge Gill, Untitled, not dated, ink on paper, $25 \times$ $10 \frac{1 / 2}{2} \mathrm{in}^{2}\left(63.5 \times 27 \mathrm{~cm}^{2}\right)$. De Stadshof Collection, Museum Dr Guislain.

over her illegitimate child. At the age of nine, Madge was sent to an orphanage and 5 years later she was shipped overseas to Canada by the orphanage as part of child-labour programme, where she worked as a farm labourer and domestic servant. She returned to London at age of 18, living with her widowed aunt Kate, a Spiritualist medium. In 1907, Madge married her cousin Thomas Gill, and although their marriage was troubled, Madge gave birth to three sons, Laurie, Reggie and Bob.

From 1918 to 1921, Gill's life tragically spiralled downward, beset by trauma. Reggie died in the influenza pandemic in 1918 at the age of 8 and later Madge suffered from severe illnesses that required the removal of her left eye and all of her teeth (Ayad, 2013). In 1921, pregnant and hoping for a daughter, she gave birth to a stillborn baby girl. The heartbroken mother nearly died of complications during the labour, and she was severely ill for months, suffering from ongoing depression and possibly a nervous breakdown (Ayad, 2013; Wojcik, 2016: 97-99).

It was in early March, 1920 that Gill first received visionary inspiration to create things, which included knitting, embroidery, writing, drawing and pianoplaying. In the mid-1920s the unseen force that guided her work was identified as the spirit Myrninerest, a name that appears as a signature on many of her drawings, and which may be derived from 'My-inner-rest' or 'Mine innerest [innermost] being.' Gill created elaborate embroidered and knitted works and then later produced ornate and delicately patterned drawings, often on the backs of postcards and scraps of notepaper. She also created huge works on unfurled rolls of plain calico fabric, some of which were more than $30 \mathrm{ft}$ in length (her largest measured $120 \mathrm{ft}$ ). These pieces were made in an ongoing and spontaneous manner, as she unrolled the cloth little by little as she progressed. The process of creativity and the related transcendent trance states captivated Gill, as she composed her drawings quickly and often produced more than a dozen designs in one evening.

In examining the thousands of artworks that Gill produced throughout her lifetime, one image unfailingly appears: a woman with a distant gaze in her eyes, a delicate nose, and tiny lips, often in a fashionable hat, surrounded by flowing shapes and geometric forms. The enigmatic expression in the eyes and on the face of this endlessly recurring figure sometimes appears melancholy or fearful, and at other times looks startled, curious or pleased (Fig. 2). Gill said that each of the faces had meanings, but she never specified what they were. The female figure may represent Gill's spirit guide, or her lost daughter, or the girls from the orphanage of her childhood, or perhaps Gill herself or an otherworldly alter ego, removed from the difficulties of her life.

In Gill's case, the loss of her son, combined with her devastating illnesses, disfigurement, the stillbirth of her daughter, and her disintegrating marriage seem to have been catalysts for creativity, which she cultivated in states of spiritual trance, leading to a consuming life of artistry. The intense concentration involved in the creative process, the complete focus of attention and engagement in artistic activity, may induce a flow-like loss of self, providing a sense of tranquillity and easing inner turmoil. Rather than necessarily associating Gill's life and art with outsider otherness and psychopathology, her artistic achievements alternatively may be interpreted as an expression of her inner strength and 
creative resourcefulness, a spirited endeavour to mitigate her experiences of childhood abandonment, the loss of loved ones and other life crises. The artistic process and Gill's involvement with Spiritualism enabled her to confront the inordinate amount of trauma in her life and create the possibility of healing and well-being to some degree. The therapeutic and spiritual meanings of her art are indicated by the fact that Gill had little interest in selling or preserving her work, as thousands of drawings were found in her home after she died, discarded in piles beneath beds and in cupboards.

Although Gill's art is singular in its mastery and complexity, it is not entirely 'outside' of culture, but was produced within the context of a global religious movement that attracted millions of believers. In her own Upton Park neighbourhood, Gill developed a reputation as a medium and held séances in her home, created astrological charts, cast horoscopes, used the Ouija broad, and offered prophecies to her neighbours. Within the Spiritualist tradition, Gill was not only creating art; her work was a communion with spirit entities who provided guidance from a higher level of existence, offering the possibility of transcendence and a direct encounter with otherworldly realms.

\section{References}

Ayad S (2013). Madge gill: a chronology. In Madge Gill: Medium and Visionary: Retrospective Exhibition, 5 October 2013-26 January 2014 (ed. M De Novellis). Orleans House Gallery: Twickenham, UK.

Wojcik D (2016). Outsider Art: Visionary Worlds and Trauma. University Press of Mississippi: Jackson.

\section{About the author}

Daniel Wojcik is a Professor of English and Folklore Studies, and affiliate faculty in Religious Studies at the University of Oregon. His books include The End of the World As We Know It: Faith, Fatalism, and Apocalypse in America (1997), Punk and Neo-Tribal Body Art (1995), and Outsider Art: Visionary Worlds and Trauma (2016), and he has published widely on the topics of millenarian worldviews, alternative spiritualties, visionary art, popular eschatology and vernacular artistic expression. Link: https://english.uoregon.edu/profile/dwojcik

Carole Tansella, Section Editor 